\title{
QUEM É SHAR EM NW E SUAS TRADUÇÕES PARA O PORTUGUÊS? UM ESTUDO DA REPRESENTAÇÃO DA PERSONAGEM BASEADO EM VALORES ATITUDINAIS
}

Taís Paulilo Blauth ${ }^{1^{*}}$

Célia Maria Magalhães ${ }^{1 * *}$

${ }^{1}$ Universidade Federal de Minas Gerais, Belo Horizonte, Minas Gerais, Brasil

\begin{abstract}
Resumo
Este trabalho se apoia na perspectiva martiniana da Linguística SistêmicoFuncional (MARTIN 1992, MARTIN; ROSE 2007) para abordar a tradução como reinstanciação interlinguística (SOUZA, 2010), adotando um enfoque interpessoal. O objetivo é estudar a representação de uma personagem da narrativa $N W$ e de suas traduções para o português e elucidar as implicações das variações semânticas para o posicionamento potencial do leitor dos textos traduzidos. A análise se baseia no sistema da Valoração (MARTIN; WHITE 2005) e o texto selecionado para a investigação é um excerto de um capítulo do romance contemporâneo britânico NW, de Zadie Smith (2012), com suas traduções em português brasileiro e europeu. A análise revela variações em maior e menor grau, principalmente de carga valorativa, em atitudes associadas à personagem. Palavras-chave: Semântica do Discurso; Valoração; Tradução literária.
\end{abstract}

\section{WHOS IS SHAR IN NW AND ITS PORTUGUESE TRANSLATIONS? A STUDY OF CHARACTER REPRESENTATION BASED ON ATTITUDINAL VALUES}

\begin{abstract}
This paper draws on the Martinian interpretation of Systemic Functional Grammar (MARTIN 1992, MARTIN; ROSE 2007) to approach translation as interlingual reinstantiation (SOUZA, 2010), from an interpersonal stance. The goal of this investigation is to examine the representation of a character of the novel in the original text and its translations to cast light on the implications of semantic variation for reader positioning.
\end{abstract}

\footnotetext{
* Tem graduação em Letras - Francês pela UFSC e, atualmente, é doutoranda e mestre pelo Programa de PósGraduação em Estudos Linguísticos da Faculdade de Letras/UFMG. Conduz pesquisas no campo dos estudos da tradução, com foco em textos literários. Seu e-mail é: blauth.tais@gmail.com. ORCID: 0000-0003-2295-0106

** Professora Titular do Programa de Pós-Graduação da Faculdade de Letras/UFMG e pesquisadora do CNPq. Tem publicado livros e capítulos de livros através de editoras (inter)nacionais e artigos em periódicos (inter) nacionais em suas áreas de interesse, semântica do discurso, multimodalidade e estudos da tradução. Seu e-mail é: cmagalhaes@ufmg.br. ORCID: 0000-0002-8494-6084.
} 
The analysis is based on the Appraisal system (MARTIN; WHITE 2005) and the text chosen for this investigation is an excerpt of a chapter of British contemporary novel NW by Zadie Smith (2012), along with its Brazilian and Portuguese translations. The analysis shows greater and lesser variations, most of loading or polarity, in attitudes associated with the character.

Keywords: Discourse Semantics; Appraisal; Literary Translation. 


\section{Introdução}

Este trabalho parte da proposta de Souza (2010) de abordar a tradução como reinstanciação interlinguística, com base em trabalhos anteriores de Martin (2006, 2008a, 2008b, 2010) sobre a hierarquia da instanciação e a reinstanciação intralinguística de textos. Dessa forma, afilia-se à vertente martiniana da Linguística Sistêmico-Funcional, concentrando-se no estrato da Semântica do Discurso segundo o modelo de língua do autor (MARTIN 1992, MARTIN; ROSE 2007).

Como Souza $(2010,2013)$, este trabalho tem enfoque interpessoal e se concentra no sistema da Valoração (MARTIN; WHITE 2005). Entretanto, o arcabouço de análise é expandido, pois o gênero utilizado na investigação é a narrativa, diferenciando-se dos textos opinativos analisados em Souza (2010, 2013). Expandindo Cristófaro (2018), Dias (2018) e Martins (2018), que estudaram padrões de valoração em reinstanciações de fases de narrativas, este trabalho analisa o funcionamento dos recursos valorativos especificamente na construção de personagens. Inclui, no estudo da tradução como reinstanciação, a complementaridade entre as hierarquias da realização e da instanciação.

O material textual usado nesta investigação constitui um recorte de um capítulo do romance contemporâneo britânico NW, de Zadie Smith (2012), e suas traduções em português brasileiro e europeu. A versão brasileira, também intitulada NW e publicada em 2014 pela Cia. das Letras, é traduzida por Sara Grünhagen; e a versão portuguesa, intitulada NW - História de Uma Cidade e publicada em 2013 pela editora D. Quixote, é traduzida por José Lima. (Os textosfonte e alvo serão doravante referidos como TF, TTBR e TTPT, respectivamente). O recorte está de acordo com o objeto do estudo relatado, o papel da Valoração na representação de uma das personagens no romance, de nome Shar.

O trabalho busca, assim, estudar a representação de uma personagem da narrativa $N W$ e suas traduções para o português da perspectiva da Valoração, e elucidar as implicações das variações semânticas nesta representação para o posicionamento potencial do leitor dos textos traduzidos.

Norteiam a investigação as seguintes perguntas de pesquisa: a) Como a personagem é construída no TF ao longo do excerto, em termos de Valoração?; b) Que variações ocorrem nos TTs e como elas afetam a construção da personagem?; e c) Que implicações essas variações têm para a leitura do texto e o posicionamento do leitor sobre a personagem?

\section{A Semântica do Discurso: conceitos subjacentes}

A perspectiva de análise do discurso adotada no presente projeto tem como base a Linguística Sistêmico-Funcional (LSF), com enfoque na Semântica do Discurso.

Na hierarquia da realização, ${ }^{1}$ a Semântica do Discurso constitui o estrato do conteúdo da linguagem. Neste estrato, a metafunção interpessoal, enfocada 
neste trabalho, diz respeito à encenação das relações sociais. A metafunção interpessoal associa-se à variável da Sintonia do estrato do contexto. A sintonia compreende a natureza das relações sociais entre interlocutores, nas dimensões complementares de poder e solidariedade (ver Fig. 1).

Figura 1 - Estratificação e Metafunção

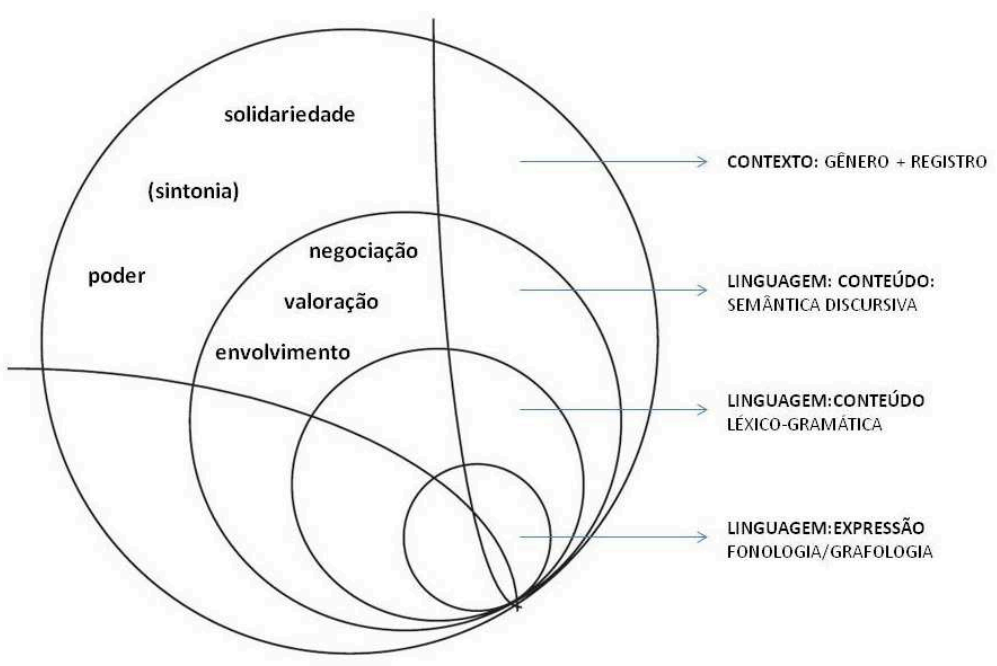

Fonte: adaptada de Martin e White (2005)

Para o estrato da Semântica do Discurso, na metafunção interpessoal, Martin (1992) e Martin e Rose (2007) propõem três sistemas, entre os quais enfoca-se o da Valoração. Este diz respeito aos significados que expressam sentimentos pessoais e institucionalizados, posicionando o falante em relação a valores no diálogo com outras vozes no texto e fora dela e, simultaneamente, antecipando o alinhamento de leitores prospectivos com estes valores.

O conceito de gênero é central na teoria adotada. Martin (1992) e Martin e Rose $(2007,2008)$, diferindo de Halliday (1978), modelam gênero no estrato da cultura para representar padrões de campo, sintonia e modo ${ }^{2}$ nos textos. Gêneros, para os autores, encenam os contextos sociais enquanto processos sociais orientados para um objetivo. Neste trabalho, interessam-nos sobretudo os gêneros narrativa (este como um dos gêneros da família das histórias, na perspectiva de Martin) e conversação casual, este como um subgênero que aparece dentro do primeiro, estando, portanto, sujeito ao valor axiológico da narrativa como um todo. A narrativa é o gênero de maior significância ideológica entre as estórias, pois pode ser empregada tanto para reforçar papéis e conjunturas sociais como para romper com o status quo (ROTHERY; STENGLIN, 1997).

Além da hierarquia da realização, é também relevante para este trabalho a hierarquia complementar da instanciação (ver MARTIN, 2008, 2008a, 2010). A instanciação relaciona sistema e texto em um contínuo de generalização ou potencialidade (como os sistemas permitidos em um sistema semiótico se agregam em subpotenciais nas instâncias de uso da linguagem), estendendo-se entre sistema, gênero/registro, tipo textual, texto e leitura. Halliday e Matthiessen 
(1999) comparam esse contínuo à relação entre tempo e clima: assim como o clima é uma generalização de padrões de tempo, o sistema seria uma generalização de padrões de instâncias. Martin acrescenta o polo da leitura à hierarquia da instanciação segundo a LSF, para indicar o significado subjetivo construído por um leitor a partir da instância. A Figura 2 ilustra a instanciação:

Figura 2 - Hierarquia da instanciação

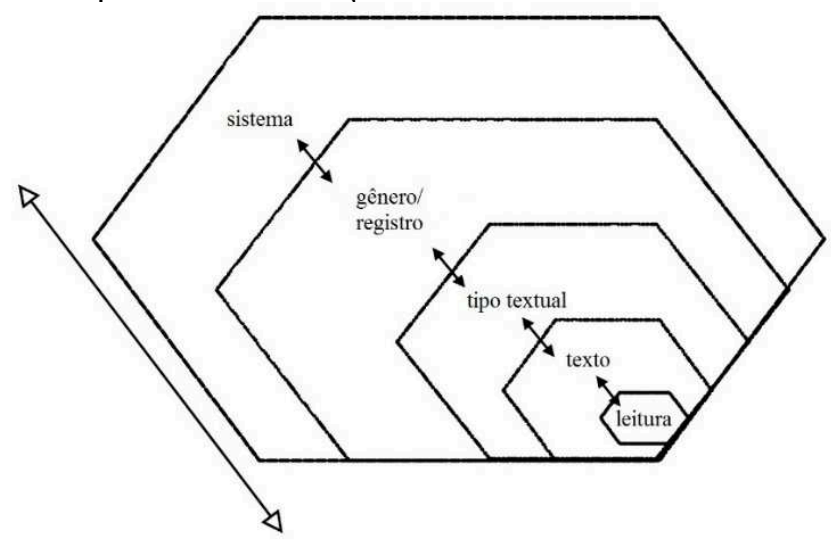

Fonte: traduzida e adaptada de Martin, 2010, p. 18

Martin (2008a, 2008b, 2010) investiga a reinstanciação de um texto em uma mesma língua (intralinguística) e, para tanto, propõe os conceitos de acoplamento e calibragem. O primeiro diz respeito à forma como os significados se associam em pares, tripletos, quartetos etc. através dos estratos, metafunções, ordens e sistemas simultâneos, permitindo uma análise que vai além de simples frequências individuais. $\mathrm{O}$ segundo, calibragem, diz respeito ao grau de especificidade do significado instanciado em um texto (seu peso semântico), e abarca o número de escolhas opcionais feitas na instanciação de um significado e seu grau de generalização. Souza (2010), citando Hood (2008), explica que a calibragem interpessoal diria respeito a padrões prosódicos, grau de explicitude e expansividade heteroglóssica. As metáforas lexicais e relações de infusão/ desinfusão de significados seriam de calibragem experiencial e interpessoal simultaneamente. Sobre a metáfora lexical, Souza (2010) explica que o caso é complexo porque, na comparação entre o significado metafórico e o literal de um termo, o metafórico tem maior calibragem ideacional ${ }^{3}$ por apresentar duas camadas de significado, mas menor calibragem interpessoal por ser menos explícito (evoca uma avaliação em vez de inscrevê-la). O significado literal, por outro lado, tem menor calibragem experiencial por conter apenas uma camada de significado, mas maior calibragem interpessoal por inscrever a avaliação.

Sobre as relações intertextuais, Martin (2006) propõe três tipos para definir o nível em que um texto reinstancia o potencial de significado de outro: citação (sobreposição total dos potenciais de ambos os textos), paráfrase (sobreposição não total) e reconto (pouco potencial comum). Nos dois últimos casos, o processo de reinstanciação envolve uma "distanciação" (MARTIN, 2008a, p. 50) ou movimento ascendente na escala da instanciação, que vai do nível da 
leitura para níveis mais gerais, para em seguida descer até os níveis do texto e da leitura na reinstanciação propriamente dita. Quanto maior a calibragem, maior a distanciação, pois é preciso subir na escala para buscar mais significado do que se encontrava na instância. Assim, um significado mais específico tem maior calibragem, enquanto um significado mais geral tem menor calibragem.

\section{A tradução como reinstanciação interlinguística}

Com base na reinstanciação intralinguística de Martin, Souza (2010) propõe entender a tradução como reinstanciação interlinguística. $\mathrm{O}$ texto traduzido é visto como leitura e instância simultaneamente e o repertório do tradutor é determinante em sua configuração. $\mathrm{Na}$ análise textual, o repertório do analista serve como referência para a comparação entre as escolhas feitas pelo tradutor e as que não o foram, mas poderiam ter sido conforme o sistema linguístico.

Souza $(2010,2013)$ discorre sobre as três hierarquias complementares da teoria - a saber, realização, instanciação e individuação - e sublinha o papel desta última (relacionada ao repertório individual), mas concentra sua análise na instanciação. Isto porque a considera uma hierarquia produtiva para as relações intertextuais, ou a forma com que um texto deriva de outro. A autora ressalta o diálogo intertextual que se estabelece entre qualquer texto e outros na mesma cultura, anteriores e posteriores, pontuando que o falante não faz escolhas diretamente a partir do potencial abstrato e ideologicamente neutro do sistema, mas dos "aglomerados metaestáveis de significados" disponíveis nos gêneros, registros e tipos textuais (SOUZA 2010, p. 142).

Souza (2010) define as relações intertextuais de Martin para a tradução como: citação (o TT é tão calibrado ideacional ou interpessoalmente quanto o TF); paráfrase (o TT é mais ou menos calibrado ideacional ou interpessoalmente do que o TF até certo ponto); reconto (o TT é mais ou menos calibrado ideacional ou interpessoalmente do que o TF em um grau maior, ou o TT calibra significados ideacionais/interpessoais diferentes). Analisando textos argumentativos de weblogs traduzidos, com foco nos significados valorativos em acoplamento com significados ideacionais e sua calibragem nos textos, constatamos que os resultados do trabalho da autora apontam para diferentes leituras prováveis a partir dos textos reinstanciados.

\section{Os significados interpessoais}

No estrato da Semântica do Discurso, o sistema da Valoração (MARTIN, 2000; WHITE, 2002; MARTIN; WHITE, 2005; MARTIN; ROSE, 2007) concerne ao posicionamento e à avaliação de um falante sobre o que está sendo negociado e seus interlocutores. Tem realização prosódica, espalhando-se pelo discurso, e envolve três sistemas simultâneos: Atitude, Engajamento e Gradação.

A Atitude pode ser ativada de modo inscrito ou evocado (representado nas análises por um $t$ de token). O modo inscrito é realizado por recursos atitudinais 
explícitos e o modo evocado inclui recursos como as metáforas lexicais ou significados ideacionais sobre os quais incide a propagação ou efeito prosódico da Valoração. Pode ter carga positiva ou negativa e se expande em níveis de delicadeza ${ }^{4}$ para os sistemas de: Afeto, relacionado às emoções; Julgamento, relacionado à ética no comportamento de pessoas; e Apreciação, relacionado à estética das coisas, pessoas e fenômenos semióticos e naturais. A Gradação intensifica ou enfraquece as avaliações atitudinais e de posicionamento, podendo se dar em termos de força (intensificação) ou foco (prototipicidade). Também pode ser realizada de forma isolada (palavra separada, como 'muito') ou fusionada (integrada ao significado da palavra, como no contínuo 'bate' - 'soca' 'esmurra') ${ }^{5}$. A Figura 3 mostra o sistema no primeiro nível de delicadeza:

Figura 3- Valoração

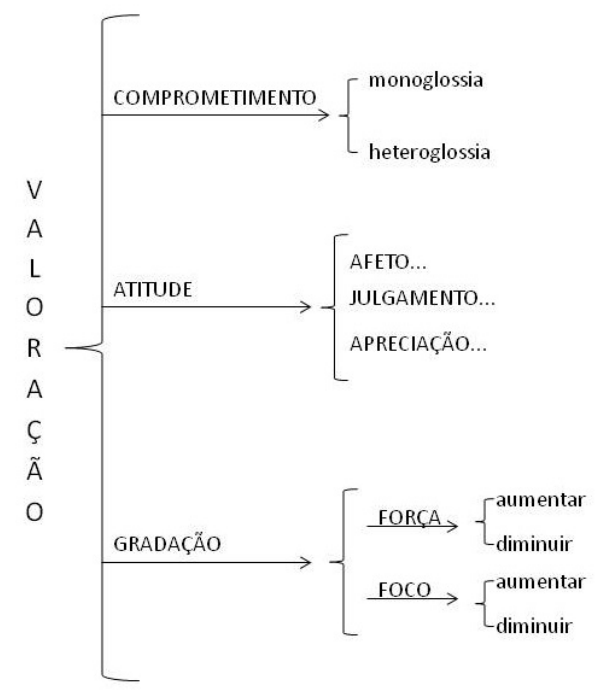

Fonte: traduzido de Martin, 2006, p. 182

\section{A Valoração na tradução de narrativas}

Não são numerosos os estudos prévios que analisam a Valoração na tradução de textos narrativos; entretanto, alguns trabalhos dialogam parcialmente com a presente investigação em seus objetivos e abordagens. Esta seção é dedicada à resenha destes estudos.

White (2016) faz um estudo exploratório de seis traduções inglesas do excerto inicial de um texto narrativo de Camus. É de interesse neste trabalho seu enfoque na experiência comunicativa dos leitores dos TTs, entendida como a totalidade dos significados potencialmente retirados do texto pelo leitor, que lhe permitem interpretações quanto à ambientação, as relações sociais e o campo da atividade humana representado. $\mathrm{O}$ autor ressalta a importância das atitudes evocadas e da carga valorativa das avaliações para suscitar uma disposição positiva ou negativa do leitor em relação a narrador e personagens.

Chang (2017) toma a noção de reinstanciação interlinguística para examinar a calibragem no romance Pride and Prejudice e traduções chinesas. 
Nos significados interpessoais, verifica que as traduções são menos calibradas ou revelam significados distintos no caso de adaptações, apontando também para diferentes calibragens entre TTs.

Dias (2018) identifica, em traduções brasileiras de textos de Chinua Achebe, variações nos acoplamentos atitudinais e a construção diferenciada de uma personagem em um TT, por acrescentar sentimentos individualizados de Afeto aos Julgamentos e Apreciações a ela acoplados no TF. Cristófaro (2018) verifica, em traduções brasileiras de contos de James Joyce, variações relacionadas à carga valorativa das avaliações, gradação e acoplamentos atitudinais, bem como na calibragem de atitudes e gradação. Martins (2018) identifica, na caracterização de pensonagens, variações relacionadas ao tipo de Valoração (reinstanciação do Afeto como Apreciação e Julgamento) e ao acoplamento entre Julgamento e Gradação, modo de ativação e instanciação de valores não instanciados no TF.

Blauth (2015) e Magalhães, Blauth e Cristófaro (2018) analisaram traduções de textos literários de língua inglesa para o português baseando-se parcialmente na Valoração. Como usaram uma perspectiva distinta, de análise de corpus, seus resultados não serão relatados neste artigo.

Assim, vê-se que os resultados já encontrados nessa linha de pesquisa são ainda incipientes e se beneficiarão da continuidade das pesquisas, particularmente no que concerne aos tipos de variações que ocorrem nas traduções de narrativas e ao que o parâmetro da calibragem pode revelar a respeito delas.

\section{Textos selecionados para o estudo}

Para explorar a Valoração na reinstanciação interlinguística de uma narrativa, toma-se um excerto do romance contemporâneo britânico $N W$, de Zadie Smith (2012), e os excertos equivalentes das traduções brasileira e portuguesa para análise.

O romance retrata a trajetória de quatro personagens na faixa dos trinta anos que habitam o distrito de NW, em Londres, bairro multicultural periférico que reúne diferentes etnias de imigrantes. O livro estrutura-se em cinco partes bastante distintas, das quais quatro são dedicadas cada uma a um personagem (Leah, Felix, Natalie e Nathan) e a última apresenta o desfecho, em que as histórias se encontram. $\mathrm{O}$ excerto tomado para este artigo integra a primeira parte (dedicada à personagem Leah e intitulada Visitation) e pode ser considerado uma narrativa por si só, por apresentar Orientação, Complicação e Resolução temporária. A personagem cuja construção textual será descrita neste trabalho é a interlocutora de Leah neste capítulo: Shar, uma jovem local.

O capítulo pode ser resumido da seguinte forma: Leah está em sua casa em um dia útil, tendo faltado ao seu trabalho no fundo de loteria local. A campainha toca e ela se depara com uma jovem desconhecida, Shar, que pede ajuda porque a mãe foi levada às pressas a um hospital após um enfarte, e ela não tem como chegar até lá. Leah a deixa entrar, lhe serve um chá e chama um táxi para levá-la ao hospital. Enquanto aguardam, as duas conversam sobre família, colegas de escola (Shar reconhece Leah como ex-colega), a casa de Leah vive, filhos, etc. 
Quando o táxi chega, Shar parte, prometendo retribuir em breve o dinheiro emprestado por Leah.

Para a análise, o excerto foi recortado a partir do capítulo tendo em vista sua produtividade para o estudo da representação da personagem da perspectiva de valores atitudinais. O relato descritivo da próxima seção apresenta os exemplos mais relevantes de variações encontrados nesse excerto.

\section{Metodologia}

A análise fez uso de planilhas eletrônicas, em conformidade com Cristófaro (2018), Dias (2018) e Martins (2018). Para isso, o excerto selecionado foi transposto para a planilha e separado por sentenças. O mesmo foi feito com os textos traduzidos, em aba adicional da mesma planilha. A Planilha da Valoração conta com colunas para Item Avaliativo, Avaliador, Atitude, Avaliado e Gradação. Destas, as de Atitude e Gradação contam com menus suspensos que listam opções a ser selecionadas. As demais são preenchidas manualmente.

O Quadro 1 apresenta as categorias da Valoração para o sistema da Atitude constantes da planilha, incluindo as opções carga positiva e negativa (CATEG.), os tipos de Valoração que essas categorias representam no âmbito do Afeto, Julgamento e Apreciação (TIPOS), sua definição conforme Martin e White $(2005)^{6}$, e exemplos do capítulo do romance original selecionado para análise que as ilustram (EXEMPLOS TF). ${ }^{7}$ Ressalta-se que, na planilha, cada categoria tem ainda as opções de modo de ativação inscrito ou evocado (esta indicada por um 't', abreviação de token).

Quadro 1 - Opções de Atitude constantes como categorias da planilha da Valoração

\begin{tabular}{|c|c|c|c|}
\hline CATEG & TIPOS & DEFINIÇÃO & EXEMPLOS TF \\
\hline $\begin{array}{l}+ \text { fel } \\
- \text { fel }\end{array}$ & $\begin{array}{l}\text { Afeto: felicidade/ } \\
\text { infelicidade }\end{array}$ & $\begin{array}{l}\text { emoções associadas a } \\
\text { questões do coração }\end{array}$ & $\begin{array}{l}\text { A woman is (...) } \\
\text { crying. } \\
\text { (-felic) }\end{array}$ \\
\hline $\begin{array}{l}+ \text { seg } \\
- \text { seg }\end{array}$ & $\begin{array}{l}\text { Afeto: segurança/ } \\
\text { insegurança }\end{array}$ & $\begin{array}{l}\text { emoções associadas ao } \\
\text { bem-estar ecossocial }\end{array}$ & $\begin{array}{l}\text { She falls foward, } \\
\text { crumpling. (t-seg) }\end{array}$ \\
\hline $\begin{array}{l}+ \text { sat } \\
\text {-sat }\end{array}$ & $\begin{array}{l}\text { Afeto: satisfação/ } \\
\text { insatisfação }\end{array}$ & $\begin{array}{l}\text { emoções associadas } \\
\text { ao telos (a busca por } \\
\text { objetivos) }\end{array}$ & $\begin{array}{l}\text { Shar isn't } \\
\text { interested. } \\
\text { (-sat) }\end{array}$ \\
\hline $\begin{array}{l}+ \text { inc } \\
\text {-inc }\end{array}$ & $\begin{array}{l}\text { Afeto: inclinação/ } \\
\text { desinclinação }\end{array}$ & $\begin{array}{l}\text { emoções associadas à } \\
\text { intenção, motivadas por } \\
\text { um Gatilho irrealis }\end{array}$ & $\begin{array}{l}\text { I just hope she's } \\
\text { OK. (+inc) }\end{array}$ \\
\hline $\begin{array}{l}\text { +norm } \\
\text {-norm }\end{array}$ & $\begin{array}{l}\text { Julgamento: } \\
\text { normalidade/ } \\
\text { anormalidade }\end{array}$ & \begin{tabular}{|l} 
"quão especial ou \\
incomum é a pessoa?"
\end{tabular} & $\begin{array}{l}\text { (He) had issues. } \\
\text { (-norm) }\end{array}$ \\
\hline $\begin{array}{l}+ \text { cap } \\
\text {-cap }\end{array}$ & $\begin{array}{l}\text { Julgamento: } \\
\text { capacidade/ } \\
\text { incapacidade }\end{array}$ & "quão capaz é a pessoa?" & She is slow. (-cap) \\
\hline
\end{tabular}




\begin{tabular}{|c|c|c|c|}
\hline $\begin{array}{l}\text { ten } \\
\text {-tem }\end{array}$ & $\begin{array}{l}\text { Julgamento: } \\
\text { tenacidade/ } \\
\text { não tenacidade }\end{array}$ & $\begin{array}{l}\text { "quão tenaz/confiável é a } \\
\text { pessoa?” }\end{array}$ & $\begin{array}{l}\text { or she is (...) } \\
\text { distracted. (-ten) }\end{array}$ \\
\hline $\begin{array}{l}+ \text { prop } \\
\text {-prop }\end{array}$ & $\begin{array}{l}\text { Julgamento: } \\
\text { propriedade/ } \\
\text { impropriedade }\end{array}$ & $\begin{array}{l}\text { "quão eticamente } \\
\text { irrepreensível é a } \\
\text { pessoa?” }\end{array}$ & $\begin{array}{l}\text { You're a really good } \\
\text { person. (+prop) }\end{array}$ \\
\hline $\begin{array}{l}\text { +ver } \\
\text {-ver }\end{array}$ & $\begin{array}{l}\text { Julgamento: } \\
\text { veracidade/ } \\
\text { inveracidade }\end{array}$ & $\begin{array}{l}\text { "quão honesta é a } \\
\text { pessoa?" }\end{array}$ & $\begin{array}{l}\text { She arranges her } \\
\text { face to signify } \\
\text { compassion. } \\
(\mathrm{t}-\mathrm{ver})\end{array}$ \\
\hline $\begin{array}{l}+ \text { rea } \\
\text {-rea }\end{array}$ & Apreciação: reação & $\begin{array}{l}\text { "isto chamou minha } \\
\text { atenção/ eu gostei } \\
\text { disso?" }\end{array}$ & $\begin{array}{l}\text { There is a wide } \\
\text { tear in the nasty } \\
\text { fabrico. (-rea) }\end{array}$ \\
\hline $\begin{array}{l}+ \text { comp } \\
\text {-comp }\end{array}$ & $\begin{array}{l}\text { Apreciação: } \\
\text { composição }\end{array}$ & $\begin{array}{l}\text { "isto está harmônico/ é } \\
\text { difícil de acompanhar?" }\end{array}$ & $\begin{array}{l}\text { Dirty heels } \\
\text { rise up out of } \\
\text { disintegrating flip- } \\
\text { flops. (-comp) }\end{array}$ \\
\hline $\begin{array}{l}+ \text { val } \\
\text {-val }\end{array}$ & $\begin{array}{l}\text { Apreciação: valor } \\
\text { social }\end{array}$ & $\begin{array}{l}\text { "o quão inovador, } \\
\text { autêntico, oportuno é } \\
\text { isto?" }\end{array}$ & $\begin{array}{l}\text { It was an } \\
\text { invaluable innings. }\end{array}$ \\
\hline
\end{tabular}

Fonte: Das autoras, 2018, com base em Martin e White, 2005.

O menu da Gradação conta com as opções para aumento e diminuição de força e foco (conforme MARTIN; WHITE, 2005): força (+), foco (+), força (-), foco (-). Como exemplos de gradação no TF, pode-se citar 'of course for Leah there is a little pleasure' para diminuição de força (força (-)) e 'proper trouble' para aumento de foco (foco $(+)$ ).

A análise partiu dos acoplamentos entre significados interpessoais e ideacionais, sendo o elemento ideacional restrito à personagem Shar na posição de Avaliador/Avaliado, e foi realizada primeiramente sobre TF, em seguida sobre TTs. A análise de variações recaiu sobre a calibragem de significados interpessoais (ou de significados ideacionais em itens valorativos, quando relevantes) e seus efeitos na caracterização da personagem. Em seguida, as reinstanciações foram classificadas em termos de citação, paráfrase ou reconto para a mensuração e exame das relações intertextuais entre TF e TTs.

O relato a seguir apresenta as variações mais relevantes na construção da personagem Shar.

\section{Construindo Shar: Valoração no texto-fonte e reinstanciações}

Nesta seção, apresenta-se cada parte relevante do excerto em suas três versões (TF, TTBR e TTPT, respectivamente) seguida do relato descritivo. As relações intertextuais são abordadas em seção posterior.

(1a) In the textured glass, a body, blurred. Wrong collection of pixels to be Michel. Between her body and the door, the hallway floor-boards, golden in reflected sun. This hallway can only lead to good things. Yet a woman is screaming PLEASE and crying. A woman thumps the front door with 
her fist. Pulling the lock aside, she finds it stops halfway, the chain pulls tight, and a little hand flies through the gap.

(1b) No vidro texturizado, um corpo, embaçado. Junção errada de pixels pra ser Michel. Entre seu corpo e a porta, o assoalho do hall de entrada, dourado pelo sol refletido. Este hall só pode levar a coisas boas. E, no entanto, uma mullher está gritando POR FAVOR e chorando. Uma mulher esmurra a porta da frente. Puxando a trava pro lado, ela descobre que ela para na metade, a corrente puxa com força, e uma mão pequena entra voando pela brecha.

(1c) No vidro granuloso, um corpo, turvo. A configuração errada de pixels para ser Michel. Entre o corpo dela e a porta, as tábuas do soalho da entrada, douradas no sol refletido. Esta entrada só pode dar para coisas boas. No entanto uma mulher está a gritar POR FAVOR e a chorar. Uma mulher bate na porta da frente com o punho. Puxando o trinco para o lado, vê que para a meio, a corrente estica, e uma mão pequena irrompe pela abertura.

Shar é introduzida no texto, antes mesmo de "aparecer em cena" quando Leah lhe abre a porta, como alguém em condição de infelicidade ("screaming", "crying") e insegurança ("thumps with her fist"). Observe-se a variação de gradação em TTBR para esta instância: enquanto o TF se concentra nos significados relativos ao modo de execução do movimento ('thump' é um som abafado, 'with her fist' descreve como foi produzido) e TTPT reinstancia essas escolhas em 'bate com o punho', TTBR não reinstancia 'with her fist' e instancia uma gradação fusionada em 'esmurra'. Assim, intensifica prosodicamente o vigor das emoções negativas vivenciadas por Shar, o que constitui um aumento de calibragem interpessoal, por indicar maior investimento no valor instanciado.

Ao longo do excerto, há variações entre os textos na construção de Shar como Avaliada, como mostram os exemplos (2) e (3) a seguir.

(2a) Shar is tiny. Her skin looks papery and dry, with patches of psoriasis on the forehead and on the jaw.

(2b) Shar é minúscula. Sua pele é seca e fina como papel, com manchas de psoríase na testa e no queixo.

(2c) Shar é minúscula. A pele parece de papel e é seca, com manchas de psoríase na testa e no queixo.

Pode-se dizer que há uma avaliação evocada na apreciação do narrador sobre Shar como 'tiny'. Na cultura britânica, que valoriza o biotipo extremamente esguio, ser chamada de 'tiny' é frequentemente um elogio, e essa inferência pode ser feita pelo leitor inglês; já o cotexto apresenta apreciações negativas sobre a pele de Shar ('dry', 'patches of psoriasis') que operam prosodicamente criando uma ambiguidade na percepção de Leah sobre sua interlocutora. ${ }^{8}$ Ambos os TTs traduzem 'tiny' por 'minúscula', o que parece representar não tanto um aumento 
de gradação ('minuscule' aparece como acepção de 'tiny' em alguns dicionários) mas uma variação na carga valorativa da avaliação. Ser 'minúscula' não costuma ser desejável no Brasil e possivelmente também não em Portugal, países que parecem valorizar corpos mais exuberantes. Em associação às avaliações negativas seguintes, a figura que se constrói de Shar nos TTs pode remeter a uma constituição esquálida, possivelmente malnutrida; mais negativa portanto, já que dificilmente evocará um valor positivo como faz 'tiny'. Em termos de calibragem, 'minúscula' não calibra mais ou menos significado do que 'tiny', mas sim um significado parcialmente diferente devido a essa implicação negativa.

Em "looks papery and dry" há variação de calibragem interpessoal em TTBR, com maior explicitude do significado de 'papery' em 'fina como papel'.' Essa variação, associada à anterior, torna a caracterização negativa de Shar mais contundente em TTBR.

O próximo exemplo apresenta novas variações de calibragem relacionadas a Shar.

(3a) Her clothes are not clean. In the back of her right knee there is a wide tear in the nasty fabrico. Dirty heels rise up out of disintegrating flipflops. She smells.

(3b) Suas roupas não estão limpas. Há um rasgo grande no feio tecido atrás do joelho direito.

Calcanhares sujos erguem-se em chinelos se desintegrando. Ela fede.

(3c) As roupas dela não estão limpas. Na parte de trás do joelho direito há um grande rasgão no tecido imundo. Cheira mal.

Primeiramente, observa-se a não reinstanciação em TTPT (3c) de uma sentença inteira, na qual se encontram as avaliações 'dirty' e 'disintegrating. Assim, a calibragem interpessoal do valor negativo é menor nesse texto, afetando a construção de Shar na medida em que a gradação por repetição de valores negativos é menor.

Ainda sobre a gradação, existe um aumento em TTPT com o sufixo '-ão' em 'rasgão', que tem o efeito contrário ao citado acima, já que aumenta localmente a calibragem interpessoal da avaliação negativa. Pode-se dizer que há um aumento localizado também em TTBR, com a escolha 'fede' para 'smells' ('fede' parece ter maior gradação em comparação a 'cheira mal', escolha também possível pelo sistema e, inclusive, adotada em TTPT). A maior gradação e calibragem interpessoal constroem Shar mais negativamente em TTBR.

As traduções do item 'nasty' em 'nasty fabrico' ilustram variações de calibragem ideacional em um item valorativo. A escolha do TF é tipicamente uma avaliação de reação negativa que pode derivar de diferentes traços do objeto avaliado. Para os propósitos do presente artigo, que se atém à calibragem interpessoal, basta apontar brevemente que os TTs têm maior calibragem ideacional por especificarem o significado: TTBR entende essa reação negativa 
como relacionada a um traço de beleza, reinstanciando-a como 'feio' - ainda entendida como avaliação de reação; TTPT a entende como relacionada a um traço de limpeza, reinstanciando-a como 'imundo' - aqui entendida como avaliação evocada de valor social, acrescida de gradação fusionada (a opção 'sujo' seria a avaliação sem gradação). A calibragem interpessoal das escolhas é a mesma por terem o mesmo nível de investimento. Em termos de construção da personagem Shar, isto significa que este item, nos TTs, atribui às suas roupas traços ligeiramente distintos, porém igualmente negativos.

A partir do início do diálogo entre Leah e Shar, esta última aparece também como Avaliadora no texto.

(4a) Leah: Have you been married long?

Shar: Too long.

Leah: Do you want me to call someone? Your husband?

Shar: Nah ... nah... he's over there. Ain't seen him in two years. Abusive. Violent. Had issues. Had a lot of problems, in his head and that. Broke my arm, broke my collarbone, broke my knee, broke my fuckin face. Tell you the truth-

(4b) Leah: Você está casada faz tempo?

Shar: Tempo demais.

Leah: Quer que eu ligue pra alguém? Seu marido?

Shar: Não. .. não... ele tá por aí. Não vejo ele faz dois anos. Grosso. Violento. Tinha uns conflitos. Um monte de problemas, na cabeça e tal. Quebrou meu braço, quebrou minha clavícula, quebrou meu joelho, quebrou minha maldita cara. Pra falar a verdade...

(4c) Leah: Estás casada há muito tempo?

Shar: Tempo de mais.

Leah: Queres que ligue para alguém? O teu marido?

Shar: Ná... ná... ele está fora. Não o vejo há dois anos. É abusador. Violento. Teve problemas. Teve uma data de problemas, na cabeça e tal. Partiu-me um braço, partiu-me a clavícula, partiu-me um joelho, partiu a porra da minha cara. Para dizer a verdade...

Algo semelhante às variações entre nasty/feio/imundo citadas anteriormente ocorre na avaliação que Shar faz de seu marido como 'abusive'. A escolha do TF é derivada de 'abuse', que inclui no sistema geral da língua inglesa as acepções de agressão física, verbal e sexual. Os TTs especificam o tipo de agressão de que se trata (verbal em 'grosso' e sexual em 'abusador'), o que constitui maior calibragem ideacional. A calibragem interpessoal pode parecer a princípio ser a mesma, já que não há variações no grau de investimento da Avaliadora neste valor. Observe-se, entretanto, que a palavra 'abusador' em português europeu raramente remete a um abuso verbal ou emocional, de modo que esse abuso será provavelmente entendido pelo leitor como de cunho sexual. ${ }^{10} \mathrm{E}$ a gravidade de uma agressão sexual em comparação a uma verbal, do ponto de vista social, tende a ser maior. Assim, considera-se que a escolha em TTPT por 'abusador' tem uma carga mais negativa do que 'abusive' no TF (em que a abrangência do termo permite um leque maior de interpretações) e 'grosso' no TT. TTPT, assim, coloca Shar na posição de vítima 
com maior eficácia, podendo suscitar uma empatia maior do leitor.

Outro tópico de conversação, também objeto da avaliação de Shar, é uma colega de escola em comum, que permanece sendo a melhor amiga de Leah. Trata-se de Natalie Blake, por nascimento Keisha, mas que mudou de nome em busca de projeção profissional. As avaliações negativas de estima social feitas por Shar sobre Natalie podem estar relacionadas a uma desconfiança ou rejeição ao sucesso profissional desta última. Os textos apresentam variações, como mostra a interação a seguir.

(5a) Shar: Got kids?

Leah: No. A dog, Olive. She's at my mate Nat's house right now. Natalie Blake? Actually in school she was Keisha. Natalie De Angelis now. In my year. Used to have a big afro puff like-

(...)

Shar: Yeah. Up herself. Coconut. Thought she was all that.

(5b) Shar: Tem filhos?

Leah: Não. Uma cachorra, Olive. Agora ela está na casa da minha amiga Nat. Natalie Blake? Na verdade na escola ela era Keisha. Natalie De Angelis agora. Do meu ano. Costumava ter um grande afro fofo como (...)

Shar: É. Cheia de si. Branca por dentro. Se achava o máximo.

(5c) Shar: Tens filhos?

Leah: Não. Uma cadela, Olive. Neste momento está em casa da Nat, a minha sócia. A Natalie Blake? Na verdade na escola era a Keisha. Agora é Natalie De Angelis. Era do meu ano. Usava uma grande cabeleira afro como...

(...)

Shar: Pois. Muito cheia de si. Mestiça. Achava-se a maior.

Em TTPT (5c) há um aumento de gradação com a instanciação de um intensificador, 'muito', acoplado à avaliação em 'cheia de si'. Essa maior calibragem interpessoal indica maior investimento de Shar no valor da avaliação que faz; ou seja, a opinião de Shar sobre Natalie é mais negativa nesse texto.

Há também variações de calibragem na tradução de 'coconut', gíria britânica que designa uma pessoa "negra por fora" mas "branca por dentro", ou seja, que renega suas origens negras ao adotar hábitos considerados característicos da sociedade branca. Entre TF e TTBR, há uma variação para menor calibragem ideacional pela não reinstanciação da imagem do côco em 'branca por dentro, ${ }^{11} \mathrm{e}$ maior calibragem interpessoal porque a atitude que é julgada negativamente pelo uso do termo (a de agir como branco) é mais facilmente inferível, mais explícita, do que o é a partir de 'coconut'.

A escolha de TTPT, 'mestiça', tem diferente calibragem interpessoal porque não carrega em seu significado ideacional o julgamento sobre a atitude desdenhosa da pessoa em relação às suas origens; a rigor, indica tão somente uma pessoa que tem ascendência mista. Entretanto, como o termo aparece em uma síndrome de avaliação negativa no exemplo citado (entre 'up herself' e 'thought 
she was all that'), recebe a influência do cotexto, formando um padrão prosódico negativo. A avaliação evocada pelo cotexto em TTPT, do ponto de vista do leitor, só pode se relacionar ao próprio fato de a pessoa ser miscigenada, portanto. Essa inferência tem implicações para questões de afiliação a comunidades, já que deve causar estranhamento ao leitor o uso de 'mestiçaem tom pejorativo por parte de Shar, dado que ela própria não pertence à comunidade branca. ${ }^{12}$

Além de Natalie, Shar avalia sua interlocutora Leah em diversos pontos do capítulo, prioritariamente de forma positiva. No exemplo a seguir, ela se refere à aparência de Leah, comparando-a com a que a colega tinha nos tempos de escola.

(6a) Shar: Yeah you looked different in school, definitely. You're better now innit. You was all ginger and bony. All long.

(6b) Shar: É, você era diferente na escola, definitivamente. Você está melhor agora, né. Você era só cabelo de fogo e osso. Toda comprida.

(6c) Shar: Lá, na escola tinhas um ar diferente, não há dúvida. Agora estás melhor, pois é? Eras toda mexida e magricela. Muito comprida.

Shar comenta que Leah costumava ser ruiva e magricela ('all ginger and bony'), para argumentar que ela está muito melhor ('much better') hoje (com efeito, ao longo de todo o capítulo Shar derrama sobre Leah diversas avaliações positivas). O item 'ginger' se assemelha ao item 'tiny' citado anteriormente. Pode ser usado de forma meramente descritiva, mas no cotexto em questão pode ser considerado como evocativo de uma avaliação negativa, dado que a característica é citada por Shar em meio a uma síndrome de valoração negativa e, com efeito, existe um preconceito contra pessoas ruivas em certos grupos sociais ingleses. Essa apreciação negativa evocada poderá ser detectada pelo leitor inglês. TTBR traduz 'ginger' por 'cabelo de fogo'. À parte o fato de essa escolha ter maior calibragem ideacional por usar uma metáfora, em termos interpessoais ela não remete a uma avaliação evocada identificável, seja de carga positiva ou negativa. Isto porque não parece existir no Brasil um preconceito contra pessoas ruivas em particular. A escolha feita em TTPT vai mais longe e parece calibrar outro significado ideacional inteiramente. 'Ginger' é traduzido como 'mexida', palavra que designa uma pessoa dinâmica, esperta, que sabe se virar na vida; uma avaliação positiva, inscrita e em nada relacionada aos cabelos de Leah, como no TF. Em TTBR e TTPT, portanto, a avaliação de Shar sobre Leah é mais neutra ou positiva, respectivamente.

Há ainda uma variação de gradação em 'all long' com a descrição ideacional 'all' (6a)/ 'toda' (6b) sendo reinstanciada em TTPT pelo intensificador 'muito' (6c), que aumenta a calibragem interpessoal da avaliação negativa sobre a altura de Leah.

O exemplo a seguir mostra Shar nas posições de Avaliadora e Avaliada, num momento em que ela reage a uma vizinha que está gritando da varanda.

(7a) Shar shakes her head and whistles. She gives Leah a look of 
neighborly sympathy.

(7b) Shar balança a cabeça e assobia. Ela dá a Leah um olhar simpático de boa vizinha.

(7c) Sha]r abana a cabeça e solta um assobio. Lança a Leah um olhar de compreensão entre vizinhas.

Na descrição do olhar lançado por Shar para Leah como 'look of neighborly sympathy', há uma avaliação de Afeto em 'sympathy' (+fel). A tradução em TTBR por 'olhar simpático de boa vizinha' apresenta duas avaliações: de Apreciação em 'simpático' (+rea) e de Julgamento em 'boa' (+prop). Há maior calibragem interpessoal pela reiteração de avaliações positivas sobre Shar. Já sobre a tradução em TTPT, 'olhar de compreensão entre vizinhas', pode-se considerar que não há avaliação, já que 'compreensão' não necessariamente indica uma disposição positiva ou negativa. A calibragem interpessoal é menor e a construção de Shar em TTBR mais positiva.

Como já dito, ao longo excerto como um todo há nas avaliações de Shar sobre Leah uma predominância de carga positiva, formando um padrão prosódico. $\mathrm{O}$ exemplo (8) a seguir mostra itens que no TF são explicitamente positivos, mas que nos TTs podem dar margem a interpretações negativas, contrastando com as demais escolhas do padrão.

(8a) Shar: Done well, though. How come you aint at work? What d'you do again?

(...)

Shar: Done well. Living right. Probably got a lot of friends, out on a Friday, clubbing, all that.

(8b) Shar: Mas se deu bem. Por que você não tá no trabalho? O que você faz mesmo?

(...)

Shar: Se saiu bem. Fazendo tudo certinho. Provavelmente tem um monte e amigos, sai na sexta, dança, coisa e tal.

(8c) Shar: Mas safaste-te bem. Como é que não estás a trabalhar? O que é que fazes afinal?

(...)

Shar: Safaste-te bem. Uma boa vida. Se calhar uma data de amigos, saídas às sextas, idas à discoteca, e essas coisas.

Em TTBR (8b), das duas ocorrências em que Shar avalia Leah como bemsucedida com 'done well', uma é traduzida por 'se deu bem' e a outra por 'se saiu bem. Enquanto a primeira pode ser categorizada como um julgamento positivo de capacidade, assim como no TF (porque apontam para a agência da pessoa em seu sucesso), 'se deu bem' é muito comumente usado no Brasil para indicar alguém que teve boa sorte sem o mérito. Pode evocar um julgamento negativo sobre essa pessoa, sugerindo sucesso por meios escusos. Em TTPT ambas as ocorrências são traduzidas por 'safaste-se bem', que, como 'se deu bem', também pode evocar 
um julgamento negativo. O mesmo tipo de insinuação está presente, ainda em TTPT, na tradução do Julgamento em 'living right' por um Afeto evocado em 'uma boa vida'. Enquanto 'right' indica algum tipo de correção ética, moral, de adequação a normas sociais, a apreciação 'boa' em 'boa vida' pode apenas evocar Afeto de felicidade, não necessariamente como resultado de esforço próprio. Essas ambiguidades nos TTs, em especial em TTPT, abrem espaço para que o leitor entenda as avaliações de Shar sobre Leah como dotadas, talvez, de algum sarcasmo, sendo portanto potencialmente mais negativas.

Ao final do excerto, há um momento de incômodo na despedida entre Shar e Leah, como mostra o Exemplo 9.

(9a) Leah grips Shar's little hand tight and submits to a kiss. Shar's mouth is slightly open on Leah's cheek for thank and now closes with you. In reply, Leah says something she has never said in her life: God bless you. They pull apart-Shar backs away awkwardly, and turns toward the car, almost gone. Leah presses the money into Shar's hand with defiance.

(9b) Leah aperta a pequena mão de Shar e se submete a um beijo. A boca de Shar está levemente aberta na bochecha de Leah para o muito e agora fecha com o obrigada. Em resposta, Leah diz algo que nunca tinha dito na vida: Deus te abençoe. Elas se separam - Shar se afasta constrangida e se volta para o carro, quase o fim. Leah mete o dinheiro na mão de Shar desafiadoramente.

(9c) Leah agarra com força a pequena mão de Shar e baixa-se para um beijo. A boca de Shar está ligeiramente aberta na cara de Leah para muito e depois fecha-se com obrigada. Em resposta, Leah diz alguma coisa que nunca antes dissera na vida: Deus te abençoe. Separam-se - Shar recua desajeitadamente, e dirige-se para o carro, prestes a partir. Leah enfia o dinheiro na mão de Shar como que em desafio.

A variação em 'awkwardly' ocorre em TTBR (9b), com a instanciação de uma valoração de Afeto negativo ('constrangida') no lugar do Julgamento negativo de TF e TTPT. Essa opção pelo Afeto imputa um sentimento a Shar naquele instante, que talvez possa ser depreendido nos outros textos apenas como avaliação evocada. O sentimento expresso em TTBR pode ser mais eficaz para suscitar a empatia do leitor do que as avaliações em TF e TTPT.

Em seguida a essa cena, ainda antes de o táxi partir, Shar faz um comentário sobre o clima para manter uma comunicação polida com Leah, sem no entanto engajar-se ativamente na interação por meio do olhar, revelando certo desconforto. ${ }^{13}$

(10a) Shar: Mental weather.

Shar uses her scarf to blot the sweat on her face, and will not look at Leah.

(10b) Shar: Clima mental.

Shar usa o lenço na cabeça pra secar o suor do rosto e de jeito nenhum olha para Leah. 
(10c) Shar: Um calor de loucos.

Shar usa o lenço para limpar o suor da cara, sem olhar para Leah.

A palavra 'mental', quando usada como aqui, como uma gíria, indica loucura, insanidade. 'Mental weather' seria um clima louco, que pelo cotexto se entende ser de calor. A tradução em TTBR, 'clima mental', não remete ao mesmo significado do TF, configurando uma variação de calibragem ideacional. Parece remeter a algo relacionado à mente e forma uma colocação estranha para o leitor brasileiro, que não consegue identificar do que se trata. Não tem uma implicação valorativa clara, indicando variação de calibragem interpessoal. Já TTPT reinstancia o significado de loucura em 'de loucos' e explicita que o clima é de calor, calibrando mais significado interpessoal. A apreciação de Shar sobre o clima é mais clara para o leitor de TTPT, o que torna também mais claro o papel desse comentário de Shar na interação com Leah, do que em TTBR.

\section{Relações intertextuais na construção de Shar}

Para determinar o grau em que os TTs calibram os significados do TF relevantes para a construção de Shar, é preciso, segundo a metodologia adotada neste artigo, classificar as variações como citações, paráfrases e recontos. O Quadro 2 a seguir apresenta essa classificação, feita na perspectiva interpessoal e a partir das considerações tecidas na análise de cada exemplo.

Quadro 2 - Variações na construção de Shar ao longo do excerto

\begin{tabular}{|l|l|l|l|l|l|l|}
\hline Trajetória & TF & TTBR & $\begin{array}{l}\text { Rel. } \\
\text { intert. }\end{array}$ & TTPT & $\begin{array}{l}\text { Rel. } \\
\text { intert. }\end{array}$ \\
\hline
\end{tabular}




\begin{tabular}{|c|c|c|c|c|c|c|}
\hline \multirow{13}{*}{$\begin{array}{l}\mathrm{O} \\
\mathrm{R} \\
\mathrm{I} \\
\mathrm{E} \\
\mathrm{N} \\
\mathrm{T}\end{array}$} & \multirow{3}{*}{$\begin{array}{l}\text { Shar aparece à } \\
\text { porta de Leah } \\
\text { em situação de } \\
\text { infelicidade/ } \\
\text { insegurança. }\end{array}$} & $\begin{array}{l}\text { 'screaming } \\
\text { PLEASE' }\end{array}$ & $\begin{array}{l}\text { 'gritando POR } \\
\text { FAVOR' }\end{array}$ & Cit. & 'a gritar POR FAVOR' & Cit. \\
\hline & & 'crying' & 'chorando' & Cit. & 'a chorar' & Cit. \\
\hline & & 'thumps' & 'esmurra' & Par. & 'bate' & Cit. \\
\hline & \multirow{4}{*}{$\begin{array}{l}\text { Shar avalia Leah } \\
\text { positivamente, } \\
\text { inclusive em } \\
\text { comparação ao } \\
\text { seu passado. }\end{array}$} & 'done well' & 'se deu bem' & Rec. & 'safaste-te bem' & Rec. \\
\hline & & 'done well' & 'se saiu bem' & Cit. & 'safaste-te bem' & Rec. \\
\hline & & 'living right' & $\begin{array}{l}\text { 'fazendo tudo } \\
\text { certinho' }\end{array}$ & Cit. & 'uma boa vida' & Par. \\
\hline & & 'ginger' & 'cabelo de fogo' & Par. & 'mexida' & Rec. \\
\hline & \multirow{3}{*}{$\begin{array}{l}\text { Na conversa, } \\
\text { Shar avalia o } \\
\text { marido e Natalie } \\
\text { negativamente. }\end{array}$} & 'abusive' & 'grosso' & Par. & 'abusador' & Par. \\
\hline & & 'up herself' & 'cheia de si' & Cit. & 'muito cheia de si' & Par. \\
\hline & & 'coconut' & $\begin{array}{l}\text { 'branca por } \\
\text { dentro' }\end{array}$ & Par. & 'mestiça' & Rec. \\
\hline & \multirow{3}{*}{$\begin{array}{l}\text { Shar é ela } \\
\text { própria avaliada } \\
\text { negativamente } \\
\text { na maior parte } \\
\text { das instâncias } \\
\text { pelo narrador. }\end{array}$} & ‘tiny' & 'minúscula' & Rec. & 'minúscula' & Rec. \\
\hline & & $\begin{array}{l}\text { 'looks papery } \\
\text { and dry' }\end{array}$ & $\begin{array}{l}\text { 'é seca e fina } \\
\text { como papel' }\end{array}$ & Par. & 'parece de papel e é seca' & Par. \\
\hline & & 'smells' & 'fede' & Par. & 'cheira mal' & Cit. \\
\hline & & 'wide tear... & 'rasgo grande...' & Cit. & 'grande rasgão...' & Par. \\
\hline & & $\begin{array}{l}\text { '...in the nasty } \\
\text { fabrico' }\end{array}$ & $\begin{array}{l}\text { '...no feio } \\
\text { tecido' }\end{array}$ & Cit. & '...no tecido imundo' & Cit. \\
\hline & & $\begin{array}{l}\text { 'dirty heels } \\
\text { rise up out of } \\
\text { disintegrating } \\
\text { flip-flops' }\end{array}$ & $\begin{array}{l}\text { 'calcanhares } \\
\text { sujos erguem- } \\
\text { se em chinelos } \\
\text { se desinte- } \\
\text { grando' }\end{array}$ & Cit. & $\varnothing$ & Rec. \\
\hline & & $\begin{array}{l}\text { 'look of } \\
\text { neighborly } \\
\text { sympathy' }\end{array}$ & $\begin{array}{l}\text { 'olhar } \\
\text { simpático de } \\
\text { boa vizinha' }\end{array}$ & Par. & $\begin{array}{l}\text { 'olhar de compreensão } \\
\text { entre vizinhas' }\end{array}$ & Par. \\
\hline \multirow{2}{*}{$\begin{array}{l}\text { R } \\
\text { E } \\
\text { S } \\
\text { O } \\
\text { L. }\end{array}$} & \multirow{2}{*}{$\begin{array}{l}\text { Quando o táxi } \\
\text { chega, Shar } \\
\text { demonstra } \\
\text { algum } \\
\text { constrangimento } \\
\text { e faz um } \\
\text { comentário } \\
\text { deslocado. }\end{array}$} & 'awkwardly' & 'constrangida' & Par. & 'desajeitadamente' & Cit. \\
\hline & & $\begin{array}{l}\text { 'mental } \\
\text { weather' }\end{array}$ & 'clima mental' & Rec. & 'calor de loucos' & Par. \\
\hline
\end{tabular}

Fonte: Das autoras 2018.

Na construção de Shar, encontram-se em ambos os TTs variações de carga valorativa nas avaliações da e sobre a personagem (ou seja, a ela acopladas nas posições de Avaliadora e Avaliada). As variações constituem paráfrases em sua maioria, alterando até certo ponto o significado interpessoal associado a ela. Quanto aos recontos, estes afetam a construção de Shar especificamente como Avaliadora ('mental' em TTBR, 'mexida' e 'mestiça' em TTPT). 'Mestiça' e 
'mexida', avaliações de Shar sobre Natalie e Leah em TTPT, calibram significados diferentes, estabelecendo "um elo com outro discurso" (SOUZA, 2010, p. 163).

Em comparação a estudos prévios sobre a Valoração, observa-se que as variações de carga valorativa parecem ser as mais autoevidentes, corroborando os resultados de White (2016), Dias (2018), Cristófaro (2018) e Martins (2018). Em relação a Martins (2018), algumas variações semelhantes afetaram a construção da personagem, mas houve também diferenças entre os estudos: como em Martins (2018), houve variação de Afeto para Julgamento ('of neighborly sympathy' para 'de boa vizinha') mas também, no sentido contrário, de Julgamento para Afeto ('awkwardly' para 'constrangida'); houve variação no acoplamento de Julgamento com Gradação ('up herself' para 'muito cheia de si'), mas as variações de gradação ocorreram também em acoplamento com Apreciações ('nasty' para 'imundo'); e não houve instanciação de um valor não instanciado no TF.

As atitudes evocadas ressaltadas por White (2016) se mostraram relevantes no presente estudo na medida em que a interpretação do tradutor sobre o valor evocado pode afetar a carga valorativa de sua escolha (como em 'minúscula' para 'tiny') ou o próprio significado reinstanciado (como em 'mexida' para 'ginger'). Com isso, o estudo concorda com Souza (2010, p. 262), para quem são necessários mais estudos sobre a individuação para se "explorar o impacto dos usuários, individualmente e como membros de diferentes comunidades (em especial tradutores) sobre o processo de reinstanciação interlinguística”.

Sobre a calibragem interpessoal, o presente estudo se diferencia do de Chang (2017) no fato de as avaliações observadas não serem menos calibradas interpessoalmente; ao contrário, há aumentos de gradação que aumentam a calibragem interpessoal, como o já citado 'muito cheia de si'. Concordando com Chang (2017), por outro lado, os TTs têm diferentes graus de calibragem entre si, como no mesmo exemplo ('cheia de si' e 'muito cheia de si').

Sobre a classificação em reconto, paráfrase e citação, proposta por Souza (2010) para as relações intertextuais entre TF e TTs com base na Valoração, é preciso fazer duas observações. A primeira é que, como aponta a autora, os limites entre cada categoria não são fáceis de definir, já que a categorização de variações em "maior" e "menor" grau de calibragem é um tanto quanto vaga. O presente estudo traz alguns exemplos que ilustram essa dificuldade, relacionada, neste caso, ao fato de as variações se encontrarem no nível dos significados evocados ou à simultaneidade de variações ideacionais e interpessoais.

Nas traduções 'minúscula' para 'tiny' e 'se deu bem' ou 'safaste-te bem' para 'done well', o que varia são as implicações potencialmente negativas das escolhas tradutórias, já que o significado ideacional é o mesmo entre TF e TTs. A diferença na carga valorativa das escolhas de TF e TTs foi entendida aqui como indicativa de reconto, com base em um exemplo semelhante de variação em Souza (2010). ${ }^{14}$ Já as traduções 'grosso' e 'abusador' para 'abusive' foram classificadas como paráfrases, pois a variação se dá na gradação (não inscrita) do Julgamento negativo que cada escolha carrega, e não na troca de uma carga positiva para 
negativa ou vice-versa. Finalmente, as traduções 'feio' e 'imundo' para 'nasty' foram classificadas como citações porque, em termos interpessoais, considerouse não haver nem variação de gradação ou explicitude, nem de carga valorativa/ significados diferentes, apesar da variação ideacional.

O que os exemplos acima ressaltam em termos de metodologia para análise de traduções é que os conceitos de calibragem ideacional e interpessoal, com suas diversas categorias de análise, exigem um grau de refinamento analítico que não encontram reflexo na classificação tripartite das relações intertextuais. Isto é, o "esmiuçamento" dos significados na análise de cada exemplo desembocam em uma classificação mais geral, em apenas três categorias, cujas definições incluem diversos "e/ou", tornando-as abrangentes. Além disso, as categorias parecem a princípio apontar para o grau em que uma escolha tradutória se afasta da escolha do TF; porém, como vimos, um reconto interpessoal pode não ser acompanhado de um reconto ideacional, de modo que uma escolha tradutória pode não ser tão facilmente classificável. Assim, o mínimo que se pode dizer a partir deste artigo é que a análise da calibragem será mais bem realizada se abranger os aspectos interpessoal e ideacional simultaneamente. Resta saber, a partir daí, se as categorias de citação, paráfrase e reconto darão conta das múltiplas nuances de significado a ser levantadas pela análise. Vale ressaltar que Martin propõe essas categorias inicialmente para a análise da reinstanciação intralingual (em uma mesma língua); é possível que a reinstanciação interlingual (entre línguas) simplesmente envolva um grau de complexidade maior e, por isso, demande categorias de análise mais refinadas.

A segunda observação a ser feita é que as categorias de citação, paráfrase e reconto são utilizadas por Souza (2010) tanto para mensurar cada escolha tradutória individualmente quanto para mensurar o texto traduzido como um todo. Sobre esta última aplicação, Souza (2010, p. 246) afirma que não se trata de uma maior frequência de determinada categoria em detrimento das outras, mas sim de "como as relações específicas interagirão no texto como um todo retórico, em contraste com o TF como todo retórico", tendo em vista o tipo de leitura projetada. Os excertos deste estudo não são representativos do romance como um todo; assim, pode-se fazer apenas uma avaliação tentativa em termos de tendências locais. Apesar das ocorrências de recontos em ambos os TTs, mais evidentes e significativas em TTPT, considera-se que os recortes dos TTs tomados cada qual como um todo não chegam a ser afetados substancialmente nos aspectos mais globais da narrativa. Por outro lado, também não apresentam sobreposição total de significados, já que as implicações de algumas variações, a depender de suas interações com outras variações ao longo do texto, podem vir a construir significados bastante distintos entre os textos. Assim, considera-se que os excertos constituem paráfrases do TF. Entre os textos, TTPT parece tender às variações semânticas mais significativas.

\section{Considerações finais}


Este artigo se ancorou no sistema semântico-discursivo da Valoração, na vertente martiniana da Linguística Sistêmico-Funcional, para enfocar a construção de uma personagem em um capítulo do romance contemporâneo $N W$, de Zadie Smith, e duas traduções em língua portuguesa, uma brasileira e uma europeia. O objetivo era examinar as variações semânticas entre os textos, no intuito de fornecer mais dados empíricos para os estudos de tradução como reinstanciação interlinguística iniciados por Souza (2010) e continuados em Dias (2018), Cristófaro e Martins (2018). Ademais, o trabalho buscava expandir esses estudos para, com o detalhamento da complementaridade entre realização e instanciação, testar a tipologia de Martin (2006) e outros para a tradução como reinstanciação linguística.

Pode-se dizer que os objetivos propostos foram atingidos, uma vez que o trabalho oferece mais dados empíricos obtidos a partir da expansão do referencial teórico-metodológico. Este permitiu interpretar os dados numa dimensão de complementaridade entre realização e instanciação e fazer uma definição tentativa do excerto estudado de acordo com os tipos de relações intertextuais propostos pela teoria.

A análise aponta também para os pontos em que a metodologia carece de expansão e aprofundamento, fornecendo exemplos claros e específicos para ilustrálos. No que concerne à classificação global do texto traduzido, uma limitação deste trabalho é ater-se a excertos bastante reduzidos; quaisquer afirmações mais contundentes exigiriam dados mais abrangentes do texto analisado. Além das questões metodológicas mais pontuais, este artigo corrobora a sugestão de Souza (2010) de que, para verificar a classificação global do texto traduzido para além do nível da suposição, seria necessário investigar a individuação (repertório, objetivos, leitura dos tradutores e leitor projetado por eles). Esse escopo de investigação, que deve ter como suporte outros recursos da metafunção interpessoal, como aqueles do Envolvimento, não foi o do presente artigo.

Para ilustrar a relevância do parâmetro da individuação, convém citar a autora de $N W$, Zadie Smith, em entrevista sobre o livro, ao ressaltar a relevância da leitura individual na construção do valor axiológico do texto:

...há uma ambivalência (...). Há um mistério. E a resposta para este mistério está muito mais nas mãos do leitor, depende de sua sensibilidade. É assim que acontece no livro. (...) Não é sobre o que é ou não verdade, mas, sim, sobre como o leitor se sente sobre esta pergunta. O que é determinante é como se organiza nosso mundo. Se as pessoas, de certa forma, naturalmente merecem o que têm. Se você acredita nisso, você organiza seus pensamentos de uma forma. Se não acredita, organiza de outra. Eu queria deixar esta questão aberta para o leitor. (SMITH, 2014)

A contribuição do trabalho aponta na direção de uma leitura/análise individual que leva em conta a intersubjetividade na tradução como reinstanciação. Esta intersubjetividade é vista a partir de um referencial teórico que oferece recursos para uma interpretação justificada dos posicionamentos: da 
autora do texto-fonte em relação aos valores nele expressos, dos tradutores que interpretam esses valores através de sua leitura e das analistas que interpretam o conjunto dos textos também através de sua leitura.

O trabalho contribui com a consolidação da linha de pesquisa de estudos de tradução como reinstanciação interlinguística, ampliando este conceito para a tradução literária. Ao estudar textos traduzidos do inglês para o português também fornece dados empíricos para esse tipo de pesquisa.

Agradecimentos: Ao Conselho Nacional de Pesquisa e Desenvolvimento (CNPq), pelo financiamento a esta pesquisa, através do projeto PQ 302123/2017-2.

\section{Notes}

1. Para uma descrição dos conceitos básicos da teoria, a saber, realização, metafunção e gênero, ver Martin (1992) e Martin e Rose (2007, 2008). Esses conceitos serão retomados nesta revisão apenas na medida em que se aplicam a este trabalho.

2. Traduções de "field", "tenor" e "mode", adotadas com base na lista de termos da teoria sistêmico-funcional traduzidos para o português (FIGUEREDO, 2011).

3. A calibragem ideacional, não detalhada aqui, diz respeito aos recursos da metafunção ideacional da linguagem, usados para construir a experiência material e mental de falantes/escritores.

4. Tradução de "delicacy", adotada com base em Figueredo (2011).

5. Exemplos de realização dos demais significados da Valoração serão apresentados nos resultados da análise.

6. Para uma descrição exaustiva, ver MARTIN;WHITE, 2005.

7. Exemplo retirado de Martin e White, 2005.

8. Convém reiterar que, em alinhamento com Souza $(2010,2013)$, o repertório do analista está sendo utilizado nesta análise como referência para contraste com as escolhas do tradutor; ou seja, as classificações aqui realizadas estão condicionadas à experiência cultural e ao repertório de língua inglesa das analistas que escrevem este trabalho.

9. Há também menor expansividade heteroglóssica na tradução de 'looks' para 'é' (que em TTBR recai sobre ambos os traços de finura e secura da pele, e em TTPT apenas sobre a secura), que torna a proposição, de fato, monoglóssica. Em TTPT o 'e’ se relaciona apenas ao traço de secura. Como esta foi a única variação que afetou o sistema do Comprometimento, esse sistema não foi abordado neste artigo.

10. O dicionário Priberam da Língua Portuguesa, de Portugal, lista como acepções o "uso excessivo de substâncias" e "o ato de ter relações sexuais com alguém sem consentimento". A acepção de "insultar" é apresentada como sendo particular ao Brasil.

11. Que ainda é uma metáfora, mas mais explícita que 'coconut'.

12. Vários recursos usados no excerto analisado, incluindo 'coconut' e suas traduções, são relevantes nas variações semânticas encontradas. No entanto, teriam de ser abordados a partir do sistema do Envolvimento, não enfocado neste trabalho.

13. A leitura dos capítulos seguintes mostra que, a despeito da promessa de Shar feita nesse capítulo, ela nunca devolve o dinheiro que pegou emprestado para o 
táxi com Leah, e talvez essa consciência é que seja a causa do constrangimento e da dificuldade em olhar para Leah. Além disso, o capítulo deixa entrever certa atração sexual de Leah para com Shar, e o beijo de despedida parece ser descrito com um erotismo sutil, que também pode explicar o movimento "awkward" de Shar ao se afastar.

14. Na variação de 'blows off' (que significa ignorar, recusar-se a perceber) para 'faz o vento levar', Souza (2010) explica que existe uma variação de polaridade, já que 'faz o vento levar' pode ser entendido como 'coloca um fim em', e aquilo que termina no texto de sua análise é algo negativo, de forma que a escolha do TT teria carga mais positiva. A conclusão a que ela chega é que significados diferentes são calibrados e, portanto, a variação pode ser classificada como reconto: "This re-instantiation in TT2 is here considered as a retelling" due to the increased possibilities of construing it. It can be construed as for example, puts an end to. In this case, the TT affords an inversion of polarity in the judgement committed in the ST. So, different ideational and interpersonal meanings would be committed in TT2". Em seu exemplo, a variação é tanto ideacional quanto interpessoal. Os exemplos deste trabalho citados acima, a despeito da sobreposição ideacional entre as escolhas de TF e TT, foram classificados como recontos por calibrarem significados interpessoais diferentes.

\section{Referências}

BLAUTH, T. P. A paisagem indizível em duas traduções brasileiras de Heart of Darkness: Uma análise de estilo baseada em corpus. 138 p. (Mestrado em Linguística Aplicada) - Faculdade de Letras, Universidade Federal de Minas Gerais, Belo Horizonte, 2015.

CHANG, C. Modelling translation as re-instantiation. Perspectives, 2017. Disponível em: < http://dx.doi.org/10.1080/0907676X.2017.1369553>.

CHRISTIE, F. \& MARTIN, J. R. (Eds). Genres and Institutions: Social Processes in the Workplace and School. London: Cassell (Open Linguistics Series), 1997.

CRISTÓFARO, N. Variações Semânticas em Duas Reinstanciações de Eveline e The Dead para o Português: um estudo baseado no sistema da valoração. Dissertação (Mestrado em Linguística Aplicada). Belo Horizonte: Faculdade de Letras da UFMG, 2018.

DIAS, C. Valoração e Variações Semânticas: um estudo das reinstanciações de estágios discursivos de Things Fall Apart e Arrow of God. Dissertação (Mestrado em Linguística Aplicada). Belo Horizonte: Faculdade de Letras da UFMG, 2018.

EGGINS, S.; SLADE, D. Analysing Casual Conversation. Cassell: London \& Washington, 1997.

FIGUEREDO, G. P. Introdução ao perfil metafuncional do português brasileiro: contribuições para os estudos multilíngues. (Tese em Linguística Aplicada) Faculdade de Letras, Universidade Federal de Minas Gerais, Belo Horizonte, 2011.

HALLIDAY, M. A. K. Language as social semiotics: the social interpretation of language and meaning. London: Edward Arnold, 1978.

HALLIDAY, M. A. K.; MATTHIESSEN, C. M. I. M. Construing Experience through Language: a language-based approach to cognition. London: Cassell, 1999.

ISAAC, A. Modelling voice as Appraisal and Involvement resources: the portrayal of textual identities and interpersonal relationships in the written stylistic analyses of non-native speaker, international undergraduates. 2012.590 f. Tese (Doutorado em Educação) - Faculdade de Educação, Universidade de Canberra, Canberra, 2012. 
MACKEN-HORARIK, M. Appraisal and the special instructiveness of narrative. Text, Adelaide, v. 2, n. 23, p. 285-312, 2003.

MAGALHÃES, C. M.; BLAUTH, T. P.; CRISTÓFARO, N. C. Mudanças na interação tradutor-leitor e intervenção tradutória em retraduções brasileiras de Os Mortos e Arábia(s): apresentação da fala e valoração em tradução. Mutatis Mutandis: Revista Latinoamericana de Traducción, Vol. 11, N. 1, Ano 2018, p. 145-171.

MARTIN, J. English text: system and structure. Philadelphia/Amsterdam: John Benjamins Publishing Companies, 1992.

MARTIN, J. Genre, ideology and intertextuality: a systemic functional perspective. Linguistics and the Human Sciences, v. 2, n. 2, 2006, p. 275-298.

MARTIN, J. Macro-genres: the ecology of the page. Context, 2015, p. 206-255.

MARTIN, J. Innocence: realisation, instantiation and individuation in a Botswanan town. In: MAHBOOB A.; KNIGHT, N. (Eds.), Questioning Linguistics. Newcastle upon Tyne, UK: Cambridge Scholars Publishing, 2008a, p. 32-76.

MARTIN, J. Tenderness: Realisation and Instantiation in a Botswanan Town. Nina Nørgaard (Ed.) 2008. Systemic Functional Linguistics in Use. Odense Working Papers in Language and Communication vol. 29, 2008b

MARTIN, J. Semantic Variation-Modelling Realisation, Instantiation and Individuation in Social Semiosis. In: BEDNAREK, M.; MARTIN, J. (Eds.) New Discourse on Language: Functional Perspectives on Multimodality, Identity, and Affiliation. London, United Kingdom: Continuum, 2010.

MARTIN, J.; ROSE, D. Working with discourse: meaning beyond the clause. 2nd ed. London: Continuum, 2007.

MARTIN, J.; ROSE, D. Genre relations: mapping culture. London: Equinox, 2008.

MARTIN, J.; WHITE, P. The Language of Evaluation: Appraisal in English. New York: Palgrave MacMillan, 2005.

MARTINS, E. A. Valoração e variações semânticas: um estudo sobre duas reinstanciações para o português de A late encounter with the enemy e The artificial nigger. Dissertação (Mestrado em Linguística Aplicada). Belo Horizonte: Faculdade de Letras da UFMG, 2018.

POYNTON, C. Address and the Semiotics of Social Relations: a Systemic-functional Account of Address Forms and Practices in Australian English. Tese (Doutorado em Linguística) Departmento de Linguística, Universidade de Sydney, 1990.

ROTHERY, J.; STENGLIN, M. Entertaining and instructing: exploring experience through story. In: CHRISTIE, F; MARTIN, J. R. (Ed.). Genre and Institutions: social processes in the workplace and school. London and New York: Continuum, 1997. p. 231-263.

ROTHERY, J.; STENGLIN, M. Interlingual re-instantiation: a new systemic functional perspective on translation. TextઐTalk, Berlin, v. 33, n. 4/5, 2013, p. 575-594.

SMITH, Z. NW. Penguin Books: New York, 2012.

SMITH, Z. NW: História de uma cidade. (Trad. José Lima) D. Quixote: Alfragide, 2013.

SMITH, Z. NW. (Trad. Sara Grünhagen). Companhia das Letras: São Paulo, 2014. Sentimentos opostos norteiam novo romance. O Estado de S. Paulo, São Paulo, 07 jun. 2014. Entrevista concedida a Ubiratan Brasil.

SOUZA, L. M. F. Interlingual re-instantiation: a model for a new and more comprehensive systemic functional perspective on translation. 2010. $339 \mathrm{f}$. 
Tese (Doutorado em Língua Inglesa) - Departamento de Língua e Literatura Estrangeiras, Universidade Federal de Santa Catarina, Florianópolis, 2010.

SOUZA, L. M. F. Interlingual re-instantiation - a new systemic-functional perspective on translation. Text \& Talk, Vol. 33, No. 4-5, 2013, p. 575-594.

WHITE, P. Constructing the "Stranger" in Camus' L'Étranger: registerial and attitudinal variability under translation. The Journal of Translation Studies, Seoul, v. 17, n. 4, 2016, p. 1-32.

Recebido: 19/10/2018

Aceito: 25/03/2019 